\title{
Conceptual Tools to Think Man
}

\author{
Fernando Almada ${ }^{1}$, Catarina Fernando ${ }^{2}$, António Vicente ${ }^{3 *}$ \\ ${ }^{1}$ Retired University Professor / Independent Researcher, Portugal \\ ${ }^{2}$ University of Madeira-CITUR, Portugal \\ ${ }^{3}$ University of Beira Interior - CIDESD, Portugal
}

Received Date: July 19, 2021; Accepted Date: July 26, 2021; Published Date: August 11, 2021

"Corresponding author: António Vicente, University of Beira Interior - CIDESD, Portugal. Email: mailto:amnv@ubi.pt

\section{Some Premises}

\section{To Build the Silogism We Stand For}

Crisis is a constant expression whatever the field, area of knowledge or context we look at, usually in a tone of regret and as if luck had abandoned us.

But crisis, as Thomas Kuhn tells us, is not something bad that we need to exorcise to improve our lives. Crisis, according to Kuhn, is an important step in the development process that alerts us to dysfunctions that we have already felt (which means that we have already identified the problem) and which leads, consequently, to search for solutions that allow us to overcome the difficulties we face.

Unless we already lack the will to continue (sign of much tiredness, which will pass with some rest, or of old age, which is not a matter of times, but of wills, which we hope has happened gone after a life full of experiences, but that, like everything, came to an end) and prefers ... to "pull over".

Crisis is what will lead us to the "new science" (Kuhn elected as the field of action knowledge and its obstacles, which came to him to find toils and misunderstandings ... challenges and areas of demand, new worlds to explore, and new reasons to continue. In this sense, it is essential to find the origin of the difficulties faced, the ways of overcoming them and, let us not forget, operationalize the solutions conceived.

\section{The Crisis}

We look and everything seems to orbit around us. The sun, the moon, evens the stars. We are at the center of everything our sight reaches. We tend to ignore what we do not see, because it's too far away, because something covers it up, because it's too small (microorganisms, dust, particles...) so that our view can detect it. Or ourselves because we need a mirror to see each other.

What we see is our world. Or, rather, from what we see (from the visual stimuli we receive), we define sensations (interpretations already), with which we construct (imagine) perceptions that we take as representations of reality.

We forget, conveniently perhaps (or sometimes), because at some point in our evolutionary process we developed the vision and, as a result of the problems we then faced, we elect it as the meaning we privilege. It would be different if we had made other choices or/and faced other difficulties. If we had preferably developed smell such as dogs, or the tact such as moles, or echolocation like bats, ... the world, this same world, would be seen (of course we should say smelled, groped, echolocated...) quite differently. And each of us would be,too, quite different.

We would have followed another route. In a process that Gordon Childe tells us a tranche, a perspective, in "Man Makes Himself", but with a dynamic that we can extrapolate to the millions of years of the evolutionary process of man and even, possibly, life in general, because nature takes advantage of the solutions achieved and, in a search for efficiency, replicates them whenever possible.

We talk and everything seems to orbit around us. My life, my car, my home, my family, my school,....

We tend to ignore that everything works in this way because we see (see, again!) things from our point of view. My point of view, your point of view, .... The perspectives are built not only for the effect we want to achieve, but also necessarily from the point of view of where we look at them.

The processes we live and live with are much more complex than we normally imagine.

But reducing the costs of the crisis forces us to go much further than many would like. Again, a matter of wills and tiredness, but also of the pleasure of searching in the unknown or the enjoyment of immobilism to contemplate, peacefully, the time to spend.

Territories of the previous two points result in multiple effects, direct, secondary or collateral.

The person in his subjectivity and individuality (the self), an identity that some forget and further ignore (or misrepresent?) the origins and reasons of its existence, does not arise from nothing or from a construction of magic. It is the result of the combination of millions of factors, in millions of years, of a multitude of experiences, triumphs and successes, but also defeats and failures.

Here, in a very brief and succinct way, we try to show the process of development of this dynamic, combining only two factors: the look and the talk, variable, but also indicators, to show only one of its effects - the notion of territory.

Konrad Lorenz, in "On Aggression" (1966), shows us the importance of defining territories as a way to restrict the need for aggressiveness. A territory, which is sometimes necessary to defend from a rival that "does not respect the rules" (which 
has nothing to do with the violence exerted to obtain food in the relationship not with a rival of the same species or similar, but with a predator or a food, is a matter of position in the "food chain"), establishes borders and delimits spaces with the dimensions that allow the feeling of security possible / necessary.

A territory does not have to be physical, as we have seen in the examples presented above of "looking" and "speaking", in which behaviors, not only in the relationship with others, but perhaps even above all, with the balances of the self (from which much of subjectivity and individuality results).

Weakness, or the feeling of weakness, leads to the desire to widen the territory, implementing the feeling of security. Man, perhaps one of the weakest animals of those who have managed to survive, is thus very aggressive as a form of defense and needs to enlarge as much as possible his different "territories" to compensate for his weaknesses.

But,attention, weakness is not the opposite of strength, of robustness. Weakness is a relationship between the cost of survival and resilience, that is the ability to resist aggression. For example - many fish, because they have a very low survival rate at low ages, breed by generating thousands of eggs. Eggs or juvenile forms that must have very low costs so that can be bearable.

There is, therefore, a dialectic of the different factors, which promotes coherences and balances, in a process that we must seek to understand in order to optimize efficiency in the way we deal with the (natural) crises we face.

\section{In Synthesis}

We have an awed in the evolutionary process of man (of life?). The crises we are experiencing today often result from poor understanding or exercise of man's functionality. Thought as one product:

- of "magic arts", attracting those who came through outer space (which may have happened, but not with the current form) and looked at the Earth and thought "that planet pleases me, we will land (literally)", in a strategy similar to that which many of the astronomers who use conditions in which "there may be life" on Earth-like planets, forgetting that there may be many types of life, as we have seen so far, in our (not on my) Earth;

- Or "spell" resulting from manipulation of terrestrial products (which may also have happened), but not in wizard cauldron that discovered wonderful potions.

Man is seen and thought of as a finished product that seeks to live eternity without having to negotiate transformations in dialectic with the context, of which it is an integral part, being able to juggle and farces to get out of the inevitable transience,dialectical debates and confrontations that make ... life.

\section{Returning To the Premises}

\section{To Build the Silogism We Stand For}

Ian Hacking defends the importance of instruments (conceptual or material) for the realization of work, particularly in situations difficult to face a crisis.

Following the suggestion, we propose as a mean of debating and seeking to understand the functionality of man, conceptual instruments that complement the debate and help to make the rupture that is imposed, that imposes the crisis on us and that we will present below.

\section{A Goal and a Strategy}

When we think of man, life in general, or any other sensitive topic (practically anything that is not basic) we must be careful not to contaminate the scene (as they say in crime films - and see the care they take to make sure that this does not happen), with artifacts that direct the investigation in directions that do not correspond to what has actually happened.

In the millions of years in which life has evolved, arrangements have been made, as we have tried to exemplify, some necessary, others only even certain at the time, which have altered narratives and ways of thinking, deforming conclusions drawn and perspectives, conditioning what we have managed to understand and the explanations that we have managed to build, causing us to lose efficiency and even make mistakes that we could otherwise avoid.

We have been publishing articles in which we try to show this theme in different perspectives, of which we present examples:

$>$ Almada, F., Fernando, C., \& Vicente, A. (2021). Science and Knowledge, Investigation and Decision at 2, 3, 4, 5, $\mathrm{n}$ Dimensions. Biomedical Journal of Scientific\& Technical Research, 35(2), 27480-27487. DOI: 10.26717/BJSTR.2021.35.005672 $\rightarrow$ In which we aim to show how science is not only not a monolith but can have different degrees of depth. A depth that we seek to serve with the proposal we make in this article with the ARAT and Mental Scheme instruments.

$>$ Almada, F., Fernando, C., \& Vicente, A. (2021). A Brief Contribution to Understand the Structure of Knowledge and the Construction of Science. Journal of Physical Fitness, Medicine \& Treatment in Sports, 8(5), 60-63. DOI: $10.19080 / J P F M T S .2021 .08 .555749 . \rightarrow$ In which we define some of the problems that we hint on in this article, showing the difficulties we felt in their construction.

$>$ Almada, F., Fernando, C., \& Vicente, A. (2020). Man: Looking for Solutions for A Huge Problem. Journal of Physical Fitness, Medicine \& Treatment in Sports, 8(4), 33-36. DOI: 10.19080/JPFMTS.2020.08.555743. $\rightarrow$ Man is the center ... of our vision of the world. Hence the importance of the concepts of ARAT and Mental Scheme for a better understanding.

$>$ Almada, F., Fernando, C., \& António, V. (2021). New Research in Science but not only. Conceptual Research on Knowledge Structures Blocking and their Causes. Novel Research in Sciences. 5(5). NRS. 000621. 2021.DOI: 10.31031/NRS.2021.05.000621 $\rightarrow$ materializing some aspects of the rupture that we intend to promote with the concepts of ARAT and Mental Scheme.

$>$ Almada, F., Fernando, C., Lopes, H., \& Vicente, A. (2019). For a Vision of Man in a Dynamic Framework: Promote Equilibrium Versus Add or Remove 'Parts' Facts, Strategies and Operational Modes. Orthopaedic Surgery and Traumatology, 2(5): 407-416. $\rightarrow$ Man is not just a part of the context, but one of its constituents. Understanding it this way is not always easy, but it is essential to understand it in its functionality, in the functionality of the global.

$>$ Almada, F., Fernando, C., \& António, V. (2020). Strategies in Knowledge Treatment, Decision-Making and Operating Conceptual Research. Biomedical Journal of Scientific \& Technical Research, 32(2), 2477-24781. $\rightarrow$ The conceptual rupture and, therefore, of the structures as well, to find ways to improve the efficiency of knowledge and its operationalization.

\section{The Rupture That We Propose}

Man, as we expose above, is not "the center of everything", nor as an individual, nor as a group, but a tiny artifact, either by its presence or by its actions, if we use as a reference a continent (which we have become accustomed to fly over, in a few hours and sleep, of course), the Earth as a whole, the Solar System, a galaxy,....

The concept of Anthropocene (the period of man! - in geological terms?), is a joke of ignorant (ignorant because it 
does not have the notion of relative proportions) that above we explain the dynamics of origins and causes, leaving the consequences to other reflections.

And yet, when the reference is situated in much more limited areas, such as the context in which our lives unfold, the 'worlds' with which we normally deal, the notion of man (not individuals) gains in dimension and appears to us under three aspects, being decisive in each of them: 1- man as a phenomenon/ object of study; 2- man as an observer, for he is the one who conducts the investigation and dominates the investigation process; 3- the man who is the 'sign' in the process, the means with which relationships are made, which with its potentialities and limitations conditions what circulates and what is blocked (for example what is visible and what only through some artifact can be found, such as radio frequencies in radio communication). Thus, we adapt to the scope with which we deal here, the triple relationship between the phenomenon/signal/observer with which Einstein made a break in physics, moving from a predominantly positivist physics to a relativistic framework.

Now the conception of man that comes to us from a frame of 'static' references and made of a set of events (paraded, isolated in a time and in a space), is not consistent with the 'dynamic' frame of reference in which we have to be situated today, so as not to lose the notion of dialectics and relationships that are established [note: the inventory of the parts of an engine does not give us the notion of its functionality; it is true that we can extrapolate from the parts, even from a few parts only, a notion of operation if we have the necessary knowledge, experience and imagination, but the risks of failure are much greater than if we see the engine running].

In this way, we must create the conditions to understand the functionality of man. The principles and laws, rules and dynamics that undertake their operation. They only mark the way in which man works, as well as the effects and consequences that result from this functioning, at the right, secondary and collateral level.

Just two tools? They'll ask a few. How is that possible? The same ones who have not yet realized that a central nuclear operation in precisely the same way as the most basic of steam engines, in which the heat of burning coal (which is the product of an agitation of molecules) has been replaced by the role of molecules obtained by radiation.

\section{Tools To Operationalize the Rupture}

- The Concept Of Mental Scheme - to understand the stabilization of the transformation process;

- The concept of A.R.A.T. - to understand the origin and operation of the transformation.

\section{Definition and Analysis of the Tools Proposed}

The simplification that we always seek to make in any research process leads us to the isolation, as far as possible, of the object of study, of the phenomenon that we intend to understand and explain.

The tools we present below, because they focus on functionality oblige us to consider and think about the dialectics that are established, that is, to become aware of the concessions and compromises made (which often become subliminal and unconscious, when they become habits in the methodologies used) so that research can take place in the conditions and within the limits of costs (which are not only financial, note) that we have to deal with.
The Concept of Mental Scheme - to understand the stabilization of the transformative process.

A proposed concept, a conceptual tool, by one of us (Almada, F.), for forty years, which has served as the subject of evidence to obtain Ph.D.

At a time when we have to remember, even if briefly, it was still considered (predominantly), for example, that: "no new neurons were generated, nor neuronal structures" (because we were being able to possess all that we were going to own, and thus we could only expect us to get less and less because they were dying - in a view of Hamon y Cajal $1852 / 1934)$, in which the animals "did not speak" trapped as they were in a Cartesian perspective of a dualism body and spirit, where positivism and its different facets were dominant, at least at the institutional level...

Mental scheme a basic structure within a structuralist conception, with a dialectical pendant. A concept of mental scheme, a conceptual tool for changing the understanding of the concept of man, because it allows to think of it from a functional perspective and not as a mere aggregate of parts that overlap, although predominantly studied independently and autonomously.

A conception that will thus respect man as a functional unit, "the self', because, having naturally a material support, it will allow to define individuality, facilitates the possibility of systematically studying the laws and principles to which the functioning of man obeys. Thus, it aims more than to describe man, to facilitate the study of its functionalities and the understanding of its dynamics.

A concept of mental scheme that also allows to understand the stabilization of the transformation process, complementing the understanding of the origin and functioning of this transformation, because although there are adaptable structures, because they are not rigid, but define trends and orientations, transformations happen.

On what basis guiding and determinations? It is to this question that we intend to answer with the proposal of the concept of A.R.A.T.

The Concept of A.R.A.T. - to understand the origin and functioning of transformation, through a process that encompasses it.

The transformations that man experiences, for example, through education, medicine, leisure, in his whole evolutionary process, etc., are not merely random. Thus, it is important to understand the dynamics with which they are carried out and the ways in which we can optimize them.

From the systematization and analysis that we have carried out in the most varied areas of knowledge that focus on the study of man (all, because man is a phenomenon/ sign / observer, as we have exposed above), we have verified and will present soon in work to be published under the title "The NextTechnological Determinant Jump", that the transformations are not the mere articulating of a stimulus/response relationship (which the phenomenon arises but that is left to it on the surface without seeking the causalities of the established dynamics, of its functionality, therefore and that, consequently, does not establish a starting platform for the deepening of the theme).

We propose, therefore, to go further, deeper into the problem, opting for a cycle that encompasses Aggression(the notion of stimulus does not delimit this aspect, because there will be stimuli that do not reach the threshold necessary to trigger the process and others that will exceed the threshold at which the process can be triggered), which will provoke a Reaction and consequently a demand for Adaptation, thereby performing the Transformation (more or less profound, permanent or transitory). 
We therefore have a functional sequence, ARAT (Aggression, Reaction, Adaptation, Transformation), which organizes and systematizes the understanding and explanation of man's functionality, that we will continue to expose different aspects and we will defend as a whole, as we've stated above, in a work to be published soon.

Citation: Almada F, Fernando C, Vicente A (2021) Conceptual Tools to Think Man. Adv Ortho and Sprts Med: AOASM-147. 